\title{
The influence of flexible management practices on the sharing of experiential knowledge in the workplace: a case study of food service helpers
}

\author{
Elise Ledoux ${ }^{\mathrm{a}}$, Esther Cloutier ${ }^{\mathrm{a}}$, Pierre-Sébastien Fournier ${ }^{\mathrm{b}}$ \\ ${ }^{a}$ Institut de recherche Robert-Sauvé en santé et sécurité du travail, 505 De Maisonneuve Blvd. West, Montreal, \\ Canada, $\mathrm{H} 3 \mathrm{~A} 3 \mathrm{C2}$ \\ ${ }^{\mathrm{b}}$ Management Department, Laval University,2325 de la Terrasse street, Quebec, Canada, G1V 0A6
}

\begin{abstract}
Previous studies have shown that the job knowledge and prudent knowledge of experienced workers constitute a wealth that needs to be shared in workplaces to promote worker integration, job retention and occupational health and safety. It appears, however, that certain management practices undermine this knowledge sharing process. This case study of food service helpers in institutional food service departments is part of a research project aimed at comparing the impact of different work organization methods on knowledge sharing in the workplace on the basis of case studies carried out in several organizations. The results of this case study reveal that by destabilizing and weakening the work teams, flexible management practices create an environment that is not conducive to experiential knowledge sharing.
\end{abstract}

Keywords: Knowledge management, flexibility, precarious work, service, work analysis

\section{Introduction}

In a context of changing demographics and a knowledge economy, concerns about age management are gradually turning into concerns about knowledge management $[10,12,14,15]$, which poses major challenges in terms of the sustainability of worker expertise (knowledge and skills) and ultimately the survival of the organization [2]. The many work strategies developed by experienced, aging workers to cope with the numerous constraints encountered in the course of their work and to protect themselves against risks to their health and safety constitute part of an organization's essential intangible assets $[1,5,8,10,13,14]$. This experiential knowledge is often invisible, highly diversified and the result of informal on-the-job learning $[3,6]$. These studies have shown that the knowledge developed by experienced workers is both varied and vast.

According to De Long [7], management practices play an important role in helping safeguard experiential knowledge in organizations. These practices concern human resource management, measures for re- taining aging workers, knowledge sharing practices and the use of information and communication technologies to preserve and share knowledge.

One increasingly frequent method of managing the workforce is the use of flexible practices, which allows organizations to adapt to changes in production demands and in their work environment.

Flexible management practices can take different forms, such as varying work schedules, salaries, and numbers of workers; or, for example, organizations requiring their workers to develop multi-tasking skills [11]. In the context of a research project aimed at comparing the impact of different work organization methods on knowledge sharing in the workplace on the basis of case studies carried out in four different organizations, we were able to document the impact that such practices can have on this process. This paper focuses specifically on the results of one of these case studies, which involved food service helpers. 


\section{Methodology}

This case study was carried out in the food service department of a Centre de santé et de services sociaux (CSSS, or health and social services centre). The CSSS includes five different establishments that have been merged over the past few years. The food service helpers are responsible for preparing food and assembling food trays, serving meals, managing food product inventories, cleaning trays, and washing dishes, as well as cleaning the premises and the work spaces. The skills involved in this occupation are essentially learned on the job.

Semi-structured interviews lasting one to two hours were conducted of four managers at different levels and a union representative. The interviews concerned the characteristics of the workers and the job; how the department operates; production constraints; the organizational changes that are under way; the interviewees' perceptions of the job of food service helper; the management practices used to promote knowledge sharing; and occupational health and safety management.

The work activities of the food service helpers were observed for four days. Their actions were documented in terms of time spent per work shift, material or equipment used, problems encountered and time spent sharing information with more experienced workers. During this observation period, the observer also spoke with the employees while they were performing their tasks to obtain more details about various aspects of the work that had attracted his or her attention.

To allow for more in-depth analysis of the knowledge sharing process, the conversations that took place between the experienced and new workers during task performance were audio-recorded. These recordings were then analyzed together with the observation data collected simultaneously in the workplace. Lastly, a group interview with three new workers gave them an opportunity to verbalize the challenges involved in learning about the job and integrating into the work team.

\section{Results}

3.1 Flexible management practices regarding work assignments

Nearly all the food service helpers observed hold atypical jobs (part-time, casual, on call) and do not have a full workload in any single food service department. To complete a full workload, they may therefore be required both to work in five different establishments and to assure their availability for four other types of functions. For each type of function, they may be assigned to different work shifts, and on each work shift they may have to occupy different work stations, each requiring mastery of a number of different tasks. This management practice has repercussions on workforce stability: the food service department has to cope with a staff turnover rate of approximately $55 \%$. The food service helpers, with the exception of a few of the more senior workers assigned to full-time jobs, are therefore required to work at a large number of work stations.

\subsection{Workers required to develop multi-tasking} skills in the context of a team activity

A widespread perception among the managers met and the union representative is that the job of food service helper does not require any specific skills and can be performed by anyone, which is often the case in numerous other non-specialized occupations.

The orientation and integration program that has been in place for only three years is reduced to a strict minimum. After an initial administrative orientation, the new food service helpers start their task training, which lasts from two to three days, depending on the establishment. They are thus introduced to each of the work stations by a designated worker during a 30 -minute period. The probation period is 30 days.

While clients' needs, ways of working and the layout of the premises vary from one establishment to the other, we identified six main categories of tasks performed by the food service helpers: preparing food, serving meals; managing food product inventories; washing dishes and trays; cleaning the premises; and opening and closing the kitchens.

Regardless of the work station or work schedule, the food service helpers are required to rotate among each of these six main tasks. For each work station, the food service helpers have to remember the location of the different products and materials used in their work; the sequences to be respected in the different tasks; the hygiene and safety procedures to be applied in different places and circumstances; clients' individual needs; information contained in the work documents; the meaning of the codes and symbols that guide them in their work (e.g. different coloured labels designating the food restrictions for diabetics, which vary from one establishment to the other). 
Our analysis also led to the identification of six action scenarios that are crucial in the performance of the food service helpers' work. These scenarios require experiential knowledge that all the helpers must develop, thus constituting strategic moments for knowledge sharing. The scenarios reveal that the work of the food service helpers is part of a dynamic process within which they must constantly adjust their actions in light of the actions of other members of the work team. The following scenarios were identified: integrating their action into the broader process under way, organizing their sequence of actions, adapting and adjusting their actions in light of the situational variables; working as a team member; interacting with the clients; and ensuring food hygiene and safety.

Consider the example of the "integrating their action into the broader process under way" scenario. Meeting production objectives requires a concerted effort on the part of the work team. A task description sheet may inform the food service helpers when to perform a given task. However, often the instructions on the sheet are not up-to-date, and when they are, they fail to take the variability of situations into account. As well, the instructions provide guidelines only and do not say how to perform the actions or why. The food service helpers must constantly keep abreast of information coming from their co-workers and the work environment to know when and how to integrate their action into the process under way. This integration implies, among other things, having an overview of the tasks in progress, knowing which activities came before or which will follow the current action, and understanding the aim of their own action and those of other workers. Both new and more senior workers recognize the importance of acquiring this knowledge that will enable them to integrate their actions. One new worker reported as follows: You have to look around to see what tasks you have to perform. A senior worker stressed the following fact to the new workers: You always have to be looking a little further ahead. Because no task stops right there... When you are portioning the food, look around to see what else is happening. Not just at your little task; you have to look at the whole picture.

Certain action scenarios are harder to master, and the experiential knowledge and skills associated with them take longer to develop. Such is the case, for example, with the "integrating their action into the broader process under way" and "interacting with clients" scenarios. Our analysis of the knowledge sharing process shows that the experiential knowledge and skills associated with these scenarios, which require more explanations and a longer coaching period on the part of experienced workers, are less often shared, even though the experienced workers develop strategies for facilitating this sharing.

\subsection{Knowledge sharing undermined by instability in the work teams}

The results of this case study reveal that it is mainly the most senior workers on the work teams, i.e. those who will soon be retiring and who hold stable jobs, who participate in sharing their experiential knowledge. The observations made of experienced but less senior workers revealed that they did yet completely master all aspects of their work even after a few years on the job. This leads them to be less involved in knowledge sharing because they fear a work overload and losing control of the situation. Their lack of availability has several consequences, one being an added burden for the most senior workers.

During orientation, the most senior workers coordinate their efforts to ensure that the new workers always have tasks to perform, that the knowledge they acquire in their tasks is as beneficial as possible for their learning process and that the pace of learning takes into account their capacity to absorb new knowledge. The experienced workers thus try to provide conditions that facilitate learning for the new workers. For example, during meal service in the cafeteria, they assign them first to serving soup, which is an easier task, before introducing them to more complex tasks. The senior workers also slow down the work pace on the conveyor: We're used to it; we don't have to run, but when a person has just arrived and is learning, you mustn't go at the same speed as usual.

The newcomers have large quantities of information to assimilate when they arrive in the food service department, and the senior workers note that only a small portion of the knowledge they share during orientation is retained: The person comes back because he or she doesn't even remember one quarter of what he or she had learned. For their part, the new workers find, when they return to the food service department after a while away, that the fact they have forgotten what they had learned has an impact on work efficiency and service quality.

The experienced workers regret the fact that they have little opportunity to see again the workers they have oriented: We wonder why we even bother giving them orientation. We hardly see them. It's like a big hole. There is a high demand for workers at the 
hospital, where they are introduced to the food service department and then to other departments, like the laundry room or the sterilization department. And then we lose sight of them. The experienced workers also recognize that work overload situations often mean that they are less available to share their knowledge, particularly when there has been largescale recruitment and they find themselves having to work with several new employees, as is often the case during the summer period.

The frequent reassignment of the new workers and the high staff turnover rates mean that the experiential knowledge-sharing process is added to the workload of the senior workers and constantly has to be repeated. This situation causes excess fatigue in these workers, which in turn lowers their motivation to participate in the knowledge sharing process.

\section{Discussion and Conclusion}

As is the case for other occupations, the knowledge sharing process cannot be dissociated from the work activities of food service helpers $[4,6,9]$. It is directly influenced by the conditions under which the work is performed, the determinants of which are found at different organizational levels. The implementation of any measure resulting in an improvement in these conditions will also promote knowledge sharing [4]. For example, the reassignment of food service helpers from one establishment to another and from one function to another means that they nearly always resume the status of "new" workers when they return to work in the food service department. This organizational determinant therefore has a major impact on occupational learning, and consequently, on work efficiency and service quality.

The contribution of experienced workers is particularly important in a context where the most senior workers with in-depth knowledge of the occupation are about to retire. The most senior workers in our case study were those who were the most heavily involved as a group in supporting occupational learning among the new workers. Yet the small number of senior workers, the lack of continuity in contacts among the members of the work teams and the weakening of the work group raise the question of a possible break in the knowledge sharing process with the food service helpers.

However, it is worth noting that in this case study the implementation of a new orientation program helped support the sharing of knowledge with the food service helpers. The fact that the program was introduced while a core of senior workers still held full-time positions constituted an advantage for the training of the new workers. That said, improvements to the program could be made with respect to the following:

- The duration of the orientation: Is it long enough, given the complexity of the knowledge and skills to be developed?

- The sharing of knowledge pertaining to the action scenarios: How can this be achieved more effectively during orientation?

- Introduction to a quick succession of compartmentalized tasks: Would it not be more beneficial to introduce new workers to only one work station in the course of any one work day?

- The heavy task borne by the senior employees who give the orientation: Could measures be put in place to lighten their production workload?

- The effectiveness of the knowledge sharing process: Could formal or informal support measures be made available to the experienced workers to help improve their effectiveness in their knowledge sharing efforts.

Lastly, to better support the knowledge sharing process, the following improvements could also be made:

- Ensuring better coordination between the food service and human resources departments regarding worker recall during the planning of the experienced/new worker buddying system and of summer replacements;

- Ensuring closer monitoring procedures during the orientation and probation periods;

- Updating the task description sheets;

- Implementing measures to minimize worker reassignments when minimal fluctuations in production needs do not justify such reassignments;

- Helping preserve a work group among the food service workers by, for example, creating moments for formal and informal dialogue among both experienced and new workers.

This case study therefore shows that knowledge sharing between experienced workers and new workers is the only means of occupational learning for food service helpers. It also shows that, given the high frequency of worker reassignment, the precarious work arrangements and the high staff turnover rate, the last senior workers to hold full-time positions are the only ones with an in-depth knowledge of the occupation. The question arises as to the impact their upcoming retirement will have on the stability of the teams, the occupational learning conditions and the preservation of occupational knowledge and 
skills if no measures are put in place to support knowledge sharing in the workplace.

\section{References}

[1] A., Avila-Asuncio, De la déficience à la gestion collective du travail: les troubles musculosqulettiques dans la restauration collective, EPHE, Paris, 1998.

[2] G., Betcherman, K., McMullen, K., Davidman, La formation et la nouvelle économie - Un rapport de synthèse, Réseaux canadien de recherche en politiques publiques, 1998.

[3] C., Chatigny, La construction de ressources opératoires. Construction à la conception des conditions de formation en situation de travail. Thèse de doctorat, Paris, Conservatoire National des Arts et Métiers, 2001.

[4] E., Cloutier, P.-S., Fournier, É. Ledoux, I., Gagnon, A., Beauvais, C., Vincent-Genod, La transmission des savoirs de métier et de prudence par les travailleurs expérimentés : comment soutenir cette approche dynamique de formation dans les milieux de travail, Rapport de recherche, IRSST, in press.

[5] E., Cloutier, H., David, E., Ledoux, M., Bourdouxhe, C. Teiger, I., Gagnon, Importance de l'organisation du travail comme soutien aux stratégies protectrices des AFS et des infirmières des services de soins et de maintien à domicile, Rapport de recherche, IRSST, 2005.

[6] E., Cloutier, S., Lefebvre, E., Ledoux, C., Chatigny, Y., StJacques, Y., Enjeux de santé et de sécurité au travail dans la transmission des savoirs professionnels: le cas des usineurs et des cuisiniers, Rapport de recherche, IRSST, 2002.

[7] D., De Long, Lost Knowledge: Confronting the threat of an aging workforce. New York: Oxford University Press, 2004
[8] P.-S., Fournier, L'aménagement de situations d'action sur le cours de vie professionnelle du camionneur : un apport à la démarche de la conception d'une formation initiale en lien avec l'activité de travail, Thèse de doctorat, Université Laval, Québec, 2003.

[9] C., Gaudart, J., Thébault, E., Cloutier, S., Volkoff. (in press). Evolutions démographiques et du travail : la transmission des savoirs professionnels entre anciens et nouveaux à l'hôpital. Rapport de recherche du CEE. http://www.ceerecherche.fr/.

[10] C., Gaudart and A., Weill-Fassina, L'évolution des compétences au cours de la vie professionnelle : une approche ergonomique, Formation Emploi 67 (1999), 47-62.

[11] D., Mercure, Nouvelles dynamiques d'entreprise et transformation des formes d'emploi- du fordisme à l'impartition flexible, in : L'incessante évolution des formes d'emploi et la redoutable stagnation des lois du travail, J., Bernier and al., (ed), Presses de l'université de Laval, Québec, 2001.

[12] M. Millanvoye and J. Colombel, Age et activité des opérateurs dans une entreprise de construction aéronautique, Actes du 31e Congrès de la SELF Intervenir par l'ergonomie, Bruxelles, 1996.

[13] S., Ouellet, N., Vézina, (2009). Savoirs professionnels et prevention des TMS : portrait de leur transmission durant la formation et perspective d'intervention, PISTES, 11 (2), (2009) $1-37$. http://www.pistes.uqam.ca/v11n2/articles/v1 ln2a4s.htm.

[14] V., Pueyo Construction et évolution des compétences: l'exemple des autocontroleurs dans la sidérurgie, Actes du 33e congrès de la SELF, Temps et travail, Paris, 1998.

[15] S., Riffaud, C., Bernier, L., Caron, Vers un transfert intergénérationnel des savoirs. Revue des études. Coproduction Alliance de recherche universités-communautés Innovations, travail et emploi, Centrale des syndicats du Québec et Syndicat des conseillères et conseillers de la CSQ, mars 2007. 